\title{
Tensile Properties of Bagasse Fiber Composites
}

\author{
Sheraz Hussain Siddique $^{1 \mathrm{a}}$, Saira Faisal ${ }^{1 \mathrm{~b}}$, Bilal Zahid ${ }^{1 \mathrm{c}}$, Chunhong Wang $^{2}$ \\ RECEIVED ON 24.06.2019, ACCEPTED ON 03.12.2019
}

\begin{abstract}
Bagasse is a waste generated in abundance from the sugarcane industry. This investigation was planned to convert bagasse waste into a useful composite. For this purpose the bagasse waste was obtained from sugar cane juice producer. In this study, the extraction of bagasse fibers was done manually and they were treated with sodium hydroxide. The treated bagasse fibers had higher tensile properties as compared to untreated ones, so the alkali treated fibers were used as reinforcement for making composites. Hand lay-up technique was used to manufacture bagasse composite samples. The fiber length $(1$ inch and 2 inch) and fiber weight percentage $(10 \mathrm{wt} \%$ and $20 \mathrm{wt} \%)$ were considered as variables. It was found that better tensile properties were obtained with higher fiber length $(2 \mathrm{inch})$ and weight percentage $(20 \mathrm{wt} \%)$. Bagasse-cotton fabric composites were also produced using cotton fabric as a base material and the bagasse fibers were sandwiched between a printed and plain cotton fabric. The idea was to consider these composites useful for sun-shades or for decorative purposes. It was also found that bagasse-cotton fabric reinforced composites had higher tensile strength and strain; however the modulus had reduced due to higher elongation of cotton fabrics. With the increase in the weight percentage the tensile properties had reduced this might be because during the composite manufacturing the epoxy resin had to pass through the fabric to wet the bagasse fiber out and they were not wetted out properly. This phenomenon needs further investigation.
\end{abstract}

Keywords: Sugarcane, Bagasse fiber, Bagasse-reinforced composite, Bagasse-cotton fabric composites, tensile properties

\section{INTRODUCTION}

$\mathrm{T}$ lextile reinforced composites are manufactured by using polymeric matrices embedded with high strength fibers as reinforcement [1]. In composites, fibers' position and orientation is maintained by polymer matrix which also guards them against the environment and possible damage, while fibers are used as the load-carrying elements to provide strength and rigidity to the composite. It is believed that a polymer matrix alone does not have essential mechanical strength, therefore, high strength fibers are used as reinforcement to provide the polymer required mechanical properties and thus make the fiber reinforced composites suitable for various applications such as ship building, agricultural products, sports equipment and aerospace [2, 3].

Synthetic fibers such as carbon, glass and aramid are commonly used as reinforcement to manufacture fiber reinforced composites. They possess high mechanical strength, however, they are expensive. These fibers are nonbiodegradable; they have higher density as compared to the polymer matrix.. Using these synthetic fibers researches are also being done to manufacture hybrid composites by mixing glass and Kevlar fabrics. These composites could be used in structural applications in aerospace

\footnotetext{
${ }^{1}$ Department of Textile Engineering, NED University of Engineering and Technology, Karachi, Pakistan.

Email: ${ }^{a}$ siddique@neduet.edu.pk, ${ }^{b}$ drsairafaisal@neduet.edu.pk (Corresponding Author), cdrbilalzahid@neduet.edu.pk

${ }^{2}$ School of Textiles, Tianjin Polytechnic University, No. 399 Bin Shui Xi Road, Xi Qing District, Tianjin 300387, China. Email: wangchunhong @ tiangong.edu.cn
}

This is an open access article published by Mehran University of Engineering and Technology, Jamshoro under CC BY 4.0 International License. 
Industry [4].

Natural fibers or lingo-cellulosic fibers such as banana, coir, kenaf and hemp fibers are gaining attention to become a possible alternate to manufacture fiber reinforced composites in the recent past [3-10]. However these fibers are being used to manufacture hybrid composites. The reason for this could be to manufacture composites which have the combination of glass and some natural fibers as reinforcement. This could help to reduce the cost and get reasonable mechanical properties $[5,6]$. This rising interest in using natural fibers as reinforcement is primarily due to their satisfactory high specific strength and modulus, availability from renewable natural resources, low cost, light weight and biodegradability. The good performance and cost effectiveness of natural fibers are able to satisfy the economic interest of industry whereas biodegradability may present a healthy ecosystem [11].

Sugar cane is the second cash crop of Pakistan. The sugar cane industry in our country is very well established. Bagasse fiber is a by-product of sugarcane industry and its availability is abundant. Sugar cane bagasse is the waste after crushing of the stalk to extract the sugar cane juice from which sugar, rum and ethanol are obtained. Bagasse fibers are obtained from different parts of the sugar cane stalk. The bagasse/stalk ratio by mass is around $40 \%$, composed of $41.7 \%$ cellulose, $28 \%$ hemicelluloses and $21.8 \%$ lignin [12]. Short fibers are located in the pith whereas; rind of the stalk is composed of long fibers. Bagasse makes a sugar industry independent in energy; the surplus bagasse can be used in paper manufacturing, animal feed, or as fibers-reinforced composites for various applications [13-16].

Natural fiber reinforced composites are enjoying wider applications in interior automotive applications such as seat back, door inner panel and roof inner panel as they provide higher acoustic damping to the automobile. In addition, an excellent opportunity can be explored for natural fibers based composites in the area of construction and building such as blocks and boards as reconstituted wood, rooftops and flooring tiles for decorative purpose can be manufactured [14].
This last trait of the use of natural fiber reinforced composites establishes the objective of this paper.

For this research work, a) bagasse fiber reinforced composites were produced and the effects of fiber weight percentage and fiber length on tensile properties were evaluated in order to check their suitability for nonstructural applications; b) bagassecotton fabric reinforced composites were produced and the effects of fiber weight percentage on tensile properties were evaluated in order to check their suitability for decorative purposes.

\section{EXPERIMENTAL}

\subsection{Materials}

Araldite LY 5052 (epoxy resin having low viscosity) along with Aradur HY5052 (a mixture of polyamines) were procured from Huntsman Pakistan. Bagasse was procured from a local sugar cane juice maker. Sodium hydroxide of analytical grade was procured from local market. Commercially printed and grey cotton fabrics (1/1 plain weave, $194 \mathrm{~g} / \mathrm{m}^{2}, 75$ ends per inch and 45 picks per inch) were procured from Mustaqim Textile Industry Karachi.

\subsection{Methods}

\subsubsection{Extraction of Bagasse Fiber}

The procured bagasse waste was dried under sunlight for 48 hours. The fibers were recovered manually.

\subsubsection{Fiber Treatment}

The solution of $4 \%$ sodium hydroxide was used to treat the extracted bagasse fibers. They were cut into a length of 1 inch and 2 inch.

\subsubsection{Composite Manufacturing}

Hand lay-up technique was used to manufacture composites samples. The process of hand lay-up used is shown schematically in Fig. 1(a-c). For this purpose, a wooden surface was covered with the plastic sheet. A box of 7 by 10 inches (width by length) was marked on it to fix the size of the composite panel.

1. Epoxy Araldite LY 5052 was then mixed with 
Aradur HY5052 at a concentration of 100:38 and a thin layer was spread on the plastic sheet.

2. The bagasse fibers as reinforcement were sprinkled randomly on the layer of epoxy resin.

3. The reinforcement was covered with another layer of epoxy resin, and the sandwich of resin and reinforcement was covered with another plastic sheet (Fig. 1b)

4. The plastic bag was sealed with the help of tape.

5. A flat plate was kept on its surface.

6. A roller was used to spread the epoxy resin in the sample.

7. A weight of $10 \mathrm{~kg}$ was used to apply pressure, remove air bubbles and to distribute the epoxy resin evenly in the sample.

For the cotton fabric and bagasse fiber composites, epoxy resin was coated on the bottom A4 size sheet. Grey cotton fabric was placed, the bagasse fibers were sprinkled randomly. A printed cotton fabric was placed on the fibers. It was finally coated with the remaining epoxy resin (Fig. 1c). The second A4 size sheet was placed on the top and pressure was applied as explained earlier.

The following variables were considered for manufacturing composites:
1. Bagasse fiber length of 1 inch and 2 inch

2. Bagasse weight percentage of $10 \mathrm{wt} \%$ and $20 \mathrm{wt} \%$

3. Bagasse cotton fabric reinforcement with $10 \mathrm{wt} \%$ and $20 \mathrm{wt} \%$ reinforcement and 2 inch bagasse fiber length

Keeping all the above variables in consideration, the bagasse-reinforced composites are categorized into six categories and the composition of each composite is shown in Table 1. The photographs of composite samples are shown in Fig. 2.

\begin{tabular}{|c|l|}
\hline \multicolumn{2}{|c|}{ Table 1: Composition of the composites } \\
\hline Symbol & \multicolumn{1}{c|}{ Composition } \\
\hline C10-1 & $\begin{array}{l}\text { Epoxy (90 wt\%)+Bagasse Fiber (Fiber } \\
\text { Length of 1 inch - 10 wt\%) }\end{array}$ \\
\hline C20-1 & $\begin{array}{l}\text { Epoxy (80 wt\%)+Bagasse Fiber (Fiber } \\
\text { Length of 1 inch - 20 wt\%) }\end{array}$ \\
\hline C10-2 & $\begin{array}{l}\text { Epoxy (90 wt\%)+Bagasse Fiber (Fiber } \\
\text { Length of 2 inch - 10 wt\%) }\end{array}$ \\
\hline C20-2 & $\begin{array}{l}\text { Epoxy (80 wt\%)+Bagasse Fiber (Fiber } \\
\text { Length of 2 inch - 20 wt\%) }\end{array}$ \\
\hline CF10-2 & $\begin{array}{l}\text { Cotton Fabric+ Epoxy (90 } \\
\text { wt\%)+Bagasse Fiber (Fiber Length of 2 } \\
\text { inch - 10 wt\%) }\end{array}$ \\
\hline CF20-2 & $\begin{array}{l}\text { Cotton Fabric+ Epoxy (80 } \\
\text { wt\%)+Bagasse Fiber (Fiber Length of 2 } \\
\text { inch - 20 wt\%) }\end{array}$ \\
\hline
\end{tabular}
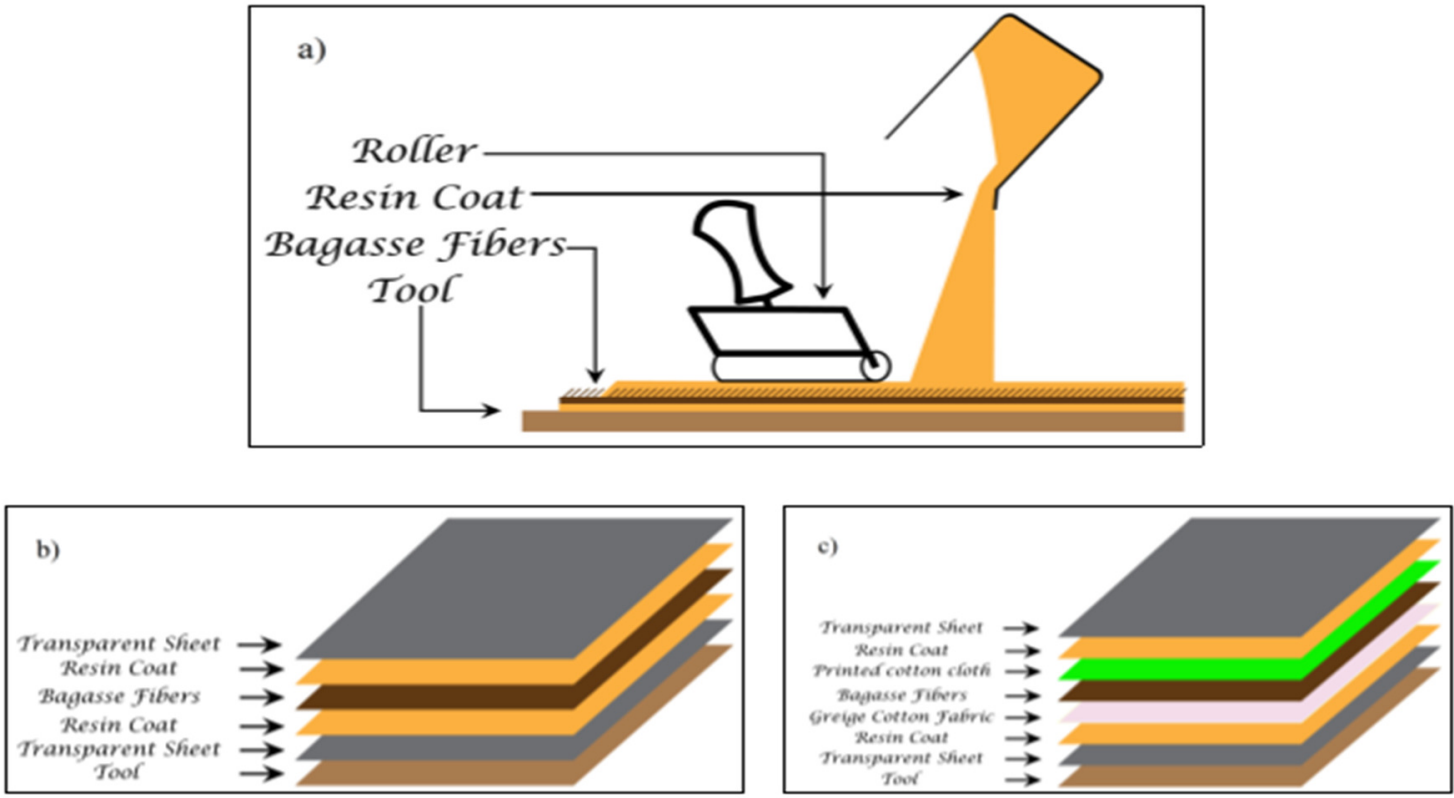

Fig. 1: Schematic layout of; a) Composite manufacturing process; b) Bagasse -reinforced composite; c) BagasseCotton Fabric reinforced Composite 


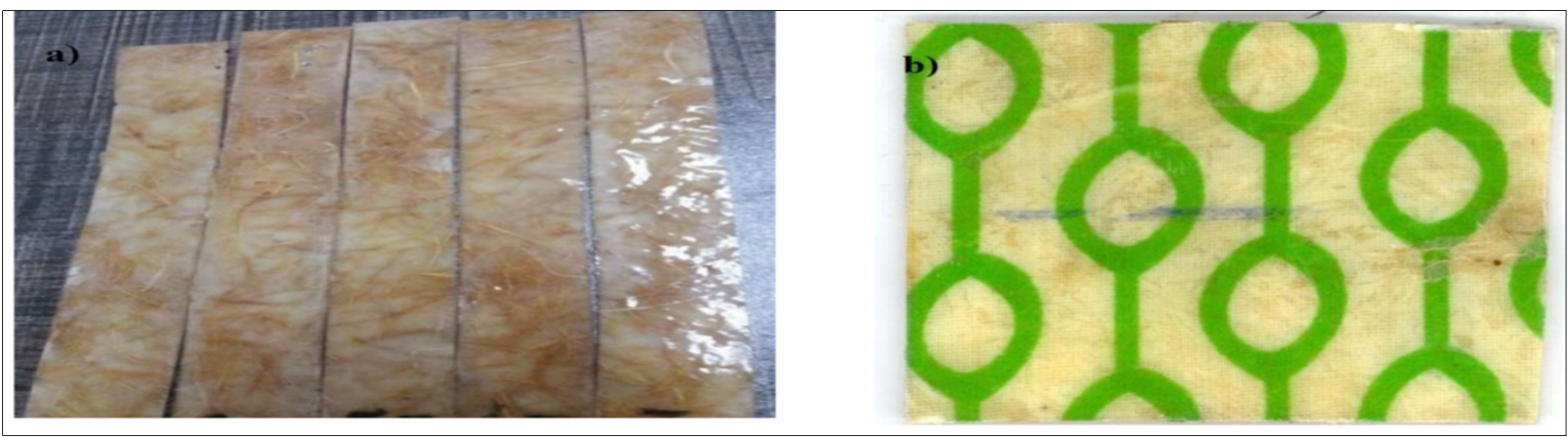

Fig. 2: Original photographs of; a) Bagasse fiber reinforced composite, b) Bagasse-cotton fabric reinforced composite

\subsection{Testing}

\subsubsection{SEM Analysis}

In order to confirm the effect of sodium hydroxide treatment on morphological characteristics of bagasse fibers; the untreated and treated fibers were characterized by using scanning electron microscopy (SEM).

\subsubsection{Tensile Testing}

The strength of untreated and treated bagasse fibers was determined by using single yarn strength tester using the standard method ASTM D2256 [17]. The fibers were dipped in $4 \%$ solution of $\mathrm{NaOH}$ for 24 hours; they were washed and dried for 24 hours under sunlight. The length of the fibers was kept constant at $0.34 \mathrm{~m}$ for the tensile tests.

The tensile strength, strain and modulus of prepared composite samples were determined using standard testing method ISO 527-4 [18]. The gauge length for the test was fixed at $150 \mathrm{~mm}$. The speed of the test was fixed at $2 \mathrm{~mm} / \mathrm{min}$. Five samples were tested for each category. The error bars are based on $95 \%$ confidence interval.

\section{RESULTS AND DISCUSSION}

\subsection{Morphology of untreated and treated bagasse Fibers}

Fig. 3 shows the SEM micrographs of untreated and treated bagasse fibers. It is evident from Fig. 3 that differences are apparent on surface morphology between untreated and sodium hydroxide treated bagasse fibres. Fig. 3a shows that the cellulose microfibrils of untreated bagasse fibers were still intact with lignin on the bagasse fiber surface whereas Fig. $3 b$ show a highly roughened surface due to the cleaning of the bagasse surface from lignin by the action of the sodium hydroxide leading to decrease of fibres diameter or an increase of the surface area and potentially improving the fiber-epoxy matrix adhesion in the composite.
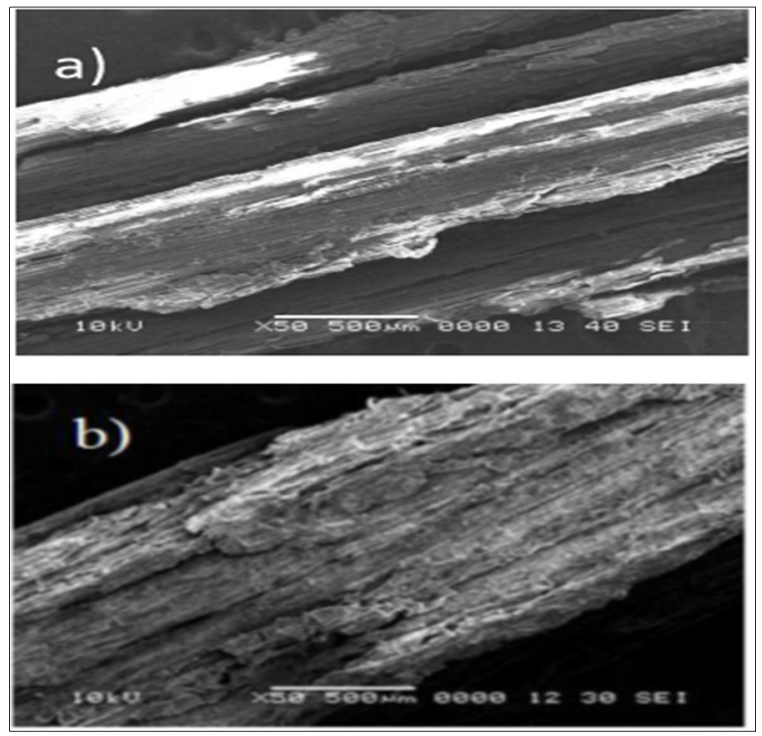

Fig. 3: SEM micrographs of; a) Untreated bagasse fibers and $b$ ) Treated bagasse fibers

\subsection{Properties of untreated and treated bagasse fibers}

The effect of alkali treatment on linear density and tenacity of bagasse fibers is shown in Table 2. It was observed from Table 2 that linear density of bagasse fibers decreased with alkali treatment, that is, the 
fineness of extracted fibers increased. This is due to the removal of waxes and other impurities and also reduction of cementing materials such as lignin, emicelluloses and pectins in cell wall of bagasse fibers [14, 19-21].

\begin{tabular}{|c|c|c|}
\hline \multicolumn{3}{|c|}{$\begin{array}{c}\text { Table 2: The Average Linear Density and Tenacity } \\
\text { of Untreated and Treated Bagasse Fibers }\end{array}$} \\
\hline Bagasse Fiber & $\begin{array}{c}\text { Linear } \\
\text { Density } \pm \text { SD } \\
(\text { Tex })\end{array}$ & $\begin{array}{c}\text { Tenacity } \pm \text { SD } \\
(\mathrm{cN} / \text { tex })\end{array}$ \\
\hline Untreated & $283( \pm 47.22)$ & $4.25( \pm 1.06)$ \\
\hline Treated & $159( \pm 45.23)$ & $8.01( \pm 2.41)$ \\
\hline
\end{tabular}

From the results shown in Table 2, it is also observed that there is an increase in tenacity of bagasse fibers after alkali treatment when compared with untreated fiber. It can be attributed to the removal of waxes and lignin from the fibers causing the increase in the tenacity $[14,19,20]$.

\subsection{Tensile properties of bagasse fiber reinforced Composites}

The stress-strain curves of bagasse-reinforced composite samples are shown in Fig. 4. It is evident from Fig. 4 that for bagasse-reinforced composites the stress varies linearly with respect to strain and no yielding is observed in most cases and composites finally fractures at their ultimate tensile strength by brittle failure.

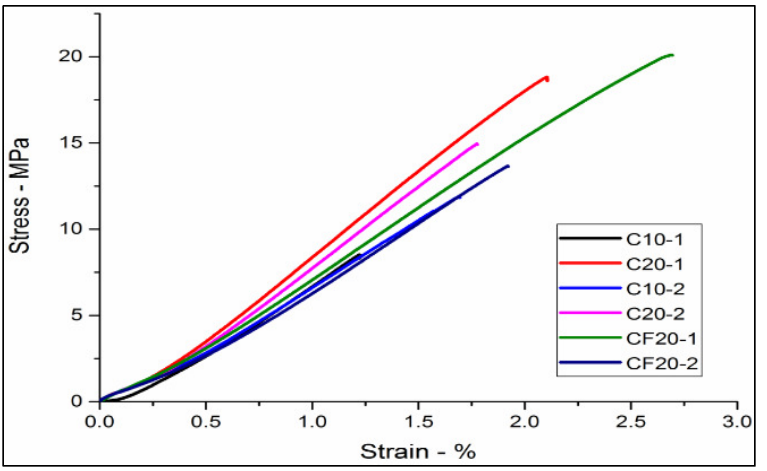

Fig. 4: Stress-strain curves for bagasse composites

The effect of fiber weight percentage and fiber length on the tensile properties of bagasse-reinforced composites is shown in Figs. 5, 6 and 7. It is evident from Fig. 5 that the tensile strength of bagasse- reinforced composites increases with increase in the fiber weight percentage irrespective of fiber length. The results showed that the mechanical interlocking was sufficient to transfer the load from the epoxy to the bagasse fibers and the reinforcing effect of the bagasse fibers prevailed. It is also observed from the Fig. 5 that as the fiber length increases the tensile strength of composites increases irrespective of fiber weight percentage. In general it is believed that the increase in the fiber length tends to increase the tensile properties of the composite samples [22-24]. This was perhaps because the longer fibers provide more surface area for the epoxy to interact. This interaction of longer fibers with the matrix will provide more resistance to the tensile force and thus will help to improve the strength. The maximum tensile strength of 17.57 MPa is observed for composites with 2 inch fiber length and $20 \mathrm{wt} \%$ fiber weight percentage. These results are also in agreement with the findings of previous studies [22, 24].

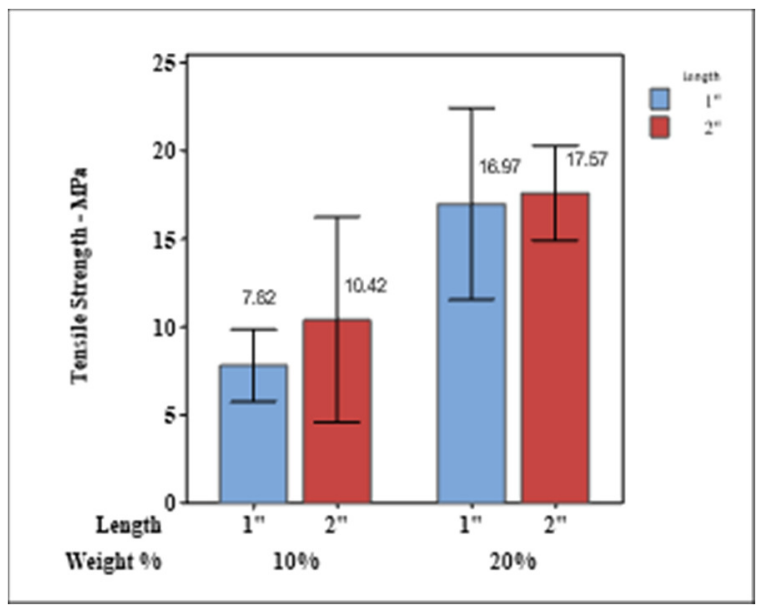

Fig. 5: Comparison of tensile strength of bagassereinforced composites samples

From Fig. 6, it can be seen that the tensile strain increases with the increase in fiber weight percentage. This could be due to enhanced bagasse fiber-epoxy bonding which promotes the load transfer to the fibers. As a result, the failure of the bagasse fiber-epoxy interface is hindered and, hence, higher strain is achieved [25]. From Fig. 6 it was also observed that at $20 \mathrm{wt} \%$ weight fraction, as the fiber length increased, the strain decreased. This may be due to a reduction in the amount of ductile epoxy available for the elongation [26]. 


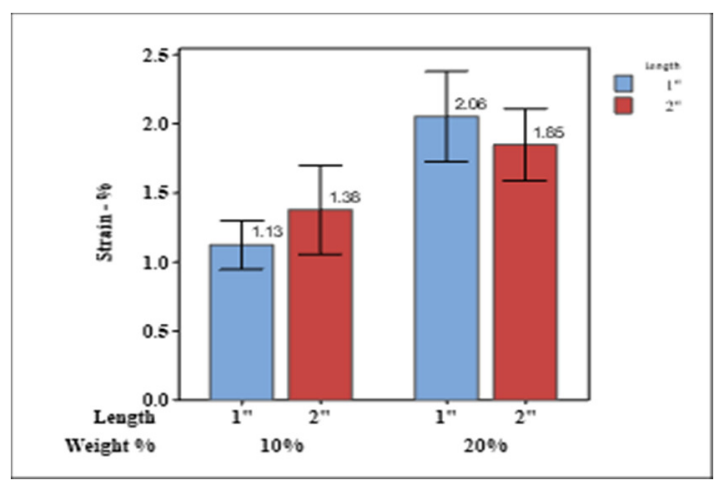

Fig. 6: Comparison of tensile strain of bagassereinforced composites samples

Fig. 7 illustrates the effect of fiber length as well as fiber weight percentage on the tensile modulus of bagasse fiber reinforced composites. It can be observed that the tensile modulus increases with the increase in fiber weight percentage irrespective of fiber length. The increase in fiber weight percentage results in increased stiffness of the composites; thus the stress-strain curve becomes steeper (Fig. 4). The poor interfacial bonding between fiber and matrix creates partially separated micro spaces that obstruct the stress propagation among them [27]. Thus, as the fiber weight percentage increases, the degree of hindrance increases, which in turn increases the stiffness. The tensile modulus of the composites also increases with the increase in fiber length. The maximum tensile modulus of $718 \mathrm{MPa}$ is obtained for composites with 2 inch fiber length and $20 \mathrm{wt} \%$ fiber weight percentage.

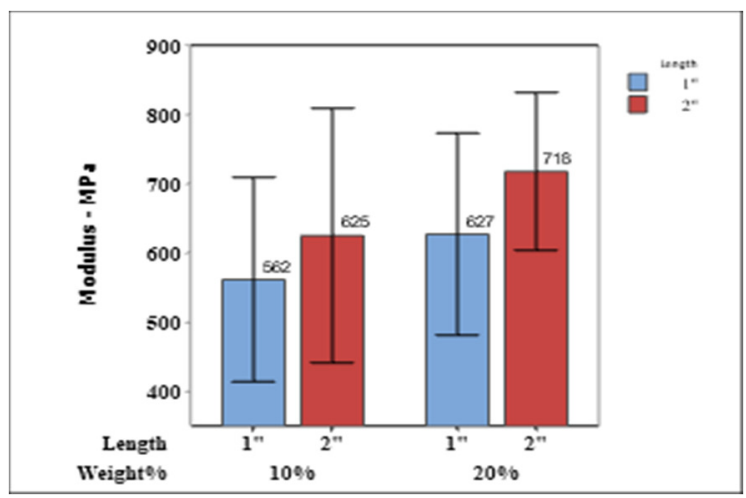

Fig. 7: Comparison of Young's Modulus of bagassereinforced composites samples

\subsubsection{Two-way ANOVA}

The tensile properties of the bagasse reinforced composites were evaluated and interpreted by using a two-way analysis of variance. Any differences between the fiber weight percentage and fiber length, or their interactions, were considered to be significant if the P-value was equal to or less than 0.05. All statistical analyses were performed on Minitab 16. The results of two-way ANOVA are shown in Table 3. The two-way ANOVA showed that only fiber weight percentage $(p<0.05)$ has significant effect on the tensile strength and tensile strain of bagasse reinforced composites whereas for Young's modulus none of the selected variable have significant effect.

\begin{tabular}{|c|c|c|c|c|c|c|}
\hline Table 3: Two way ANOVA of Tensile Properties of Bagasse-Reinforced Composites \\
\hline Tensile Properties & Source & DF & SS & MS & F & P \\
\hline Tensile Strength & Weight & 1 & 331.787 & 331.787 & 27.38 & $0.000^{*}$ \\
\hline & Length & 1 & 12.800 & 12.800 & 1.06 & 0.319 \\
\cline { 2 - 8 } & Interaction & 1 & 4.980 & 4.980 & 0.41 & 0.531 \\
\hline & Error & 16 & 193.863 & 12.116 & & \\
\cline { 2 - 8 } & Total & 19 & 543.430 & & & \\
\hline \multirow{5}{*}{ Tensile Strain } & Weight & 1 & 2.45490 & 2.45490 & 48.96 & $0.000^{*}$ \\
\hline & Length & 1 & 0.00295 & 0.00295 & 0.06 & 0.811 \\
\hline & Interaction & 1 & 0.26335 & 0.26335 & 5.25 & 0.036 \\
\cline { 2 - 8 } & Error & 16 & 0.80223 & 0.05014 & & \\
\cline { 2 - 7 } & Total & 19 & 3.52343 & & & \\
\hline Young's Modulus & Weight & 1 & 31319 & 31318.9 & 2.15 & 0.162 \\
\hline & Length & 1 & 29602 & 29601.9 & 2.03 & 0.173 \\
\hline & Interaction & 1 & 929 & 929.4 & 0.06 & 0.804 \\
\hline & Error & 16 & 233215 & 14575.9 & & \\
\cline { 2 - 7 } & Total & 19 & 295065 & & & \\
\hline
\end{tabular}




\subsection{Tensile properties of bagasse-cotton fabric reinforced polymer composites}

In this research work a new type of composite material was manufactured which comprises of bagasse fibers and cotton fabric as reinforcing materials. Keeping the results of two-way ANOVA in view (see Table 3), fiber weight percentage was selected as a variable keeping the fiber length constant at 2 inch. The bagasse fibers were sandwiched between two fabric purposes. A cotton printed fabric was used for this purpose on the top and a plain cotton fabric was used on the bottom. The idea behind this technique was to form composite samples, which can be utilized as sun shades in the gardens or as decorative purposes. The tensile properties of both type of composite are compared and are shown in Figs. 8 and 9. Also, the tensile properties of bagasse- cotton reinforced composites are compared and results are shown in Fig. 10. For the comparisons of tensile properties of manufactured composites paired t-test was also conducted to determine the significance of the differences between two sets of samples.

It is observed from Fig. 8 that the tensile strength and tensile strain of the CF10-2 was higher as compared to the C10-2. Higher value of tensile strength could be due to improved bonding between cotton fabric and epoxy resin whereas higher tensile strain could be attributed to the higher elongation of cotton fabric. It is also evident from Fig. 8 that the tensile modulus of CF10-2 had decreased as compared to C10-2. Since the bagasse-cotton fabric composites had higher strain resulting in the reduction of the tensile modulus.

Concerning the paired t-test results, significant difference is found in tensile strength $(\mathrm{T}-\mathrm{V}$ alue $=6.86$; $\mathrm{P}$-Value $=0.002)$ and tensile strain $(\mathrm{T}-$ Value $=8.10$; $\mathrm{P}-$ Value $=0.001$ ) properties between two samples whereas there no significant difference in young's modulus $(\mathrm{T}-$ Value $=-2.71 ; \mathrm{P}-$ Value $=0.054)$ between two samples.

From Fig. 9 it is evident that for CF20-2 the tensile strength slightly decreases as compared to C20-2. Moreover, tensile strain of $\mathrm{CF} 20-2$ was slightly increased as compared to C20-2. This could be attributed to the higher elongation of cotton fabric. Furthermore, it is also observed from Fig. 9 that the tensile modulus of CF20-2 had decreased. Since the CF20-2 had higher strain resulting in the reduction of the tensile modulus.

Paired t-test results suggested that significant difference is found in young's modulus ( $\mathrm{T}$-Value $=-$ 3.79; $\quad \mathrm{P}$-Value $=0.019$ ) whereas no significant difference was found in tensile strength ( $T-V a l u e=-$ 1.43; P-Value=0.226) and tensile strain ( $\mathrm{T}$ Value $=1.34 ; \mathrm{P}-$ Value $=0.252$ ) between two samples.
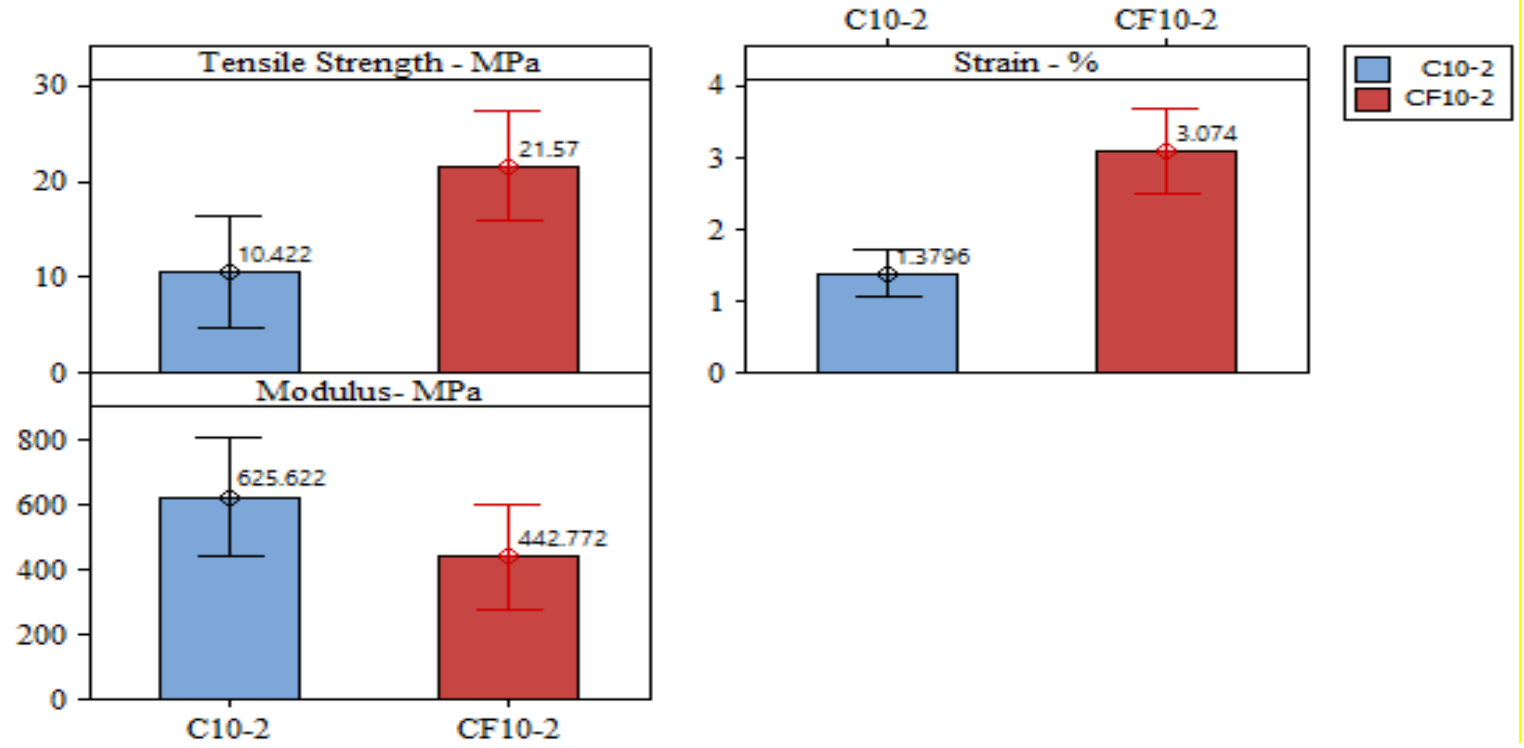

Fig. 8: Tensile Properties for Composites C10-2 (bagasse fiber reinforced) and CF10-2 (bagasse-cotton fabric reinforced composite) 

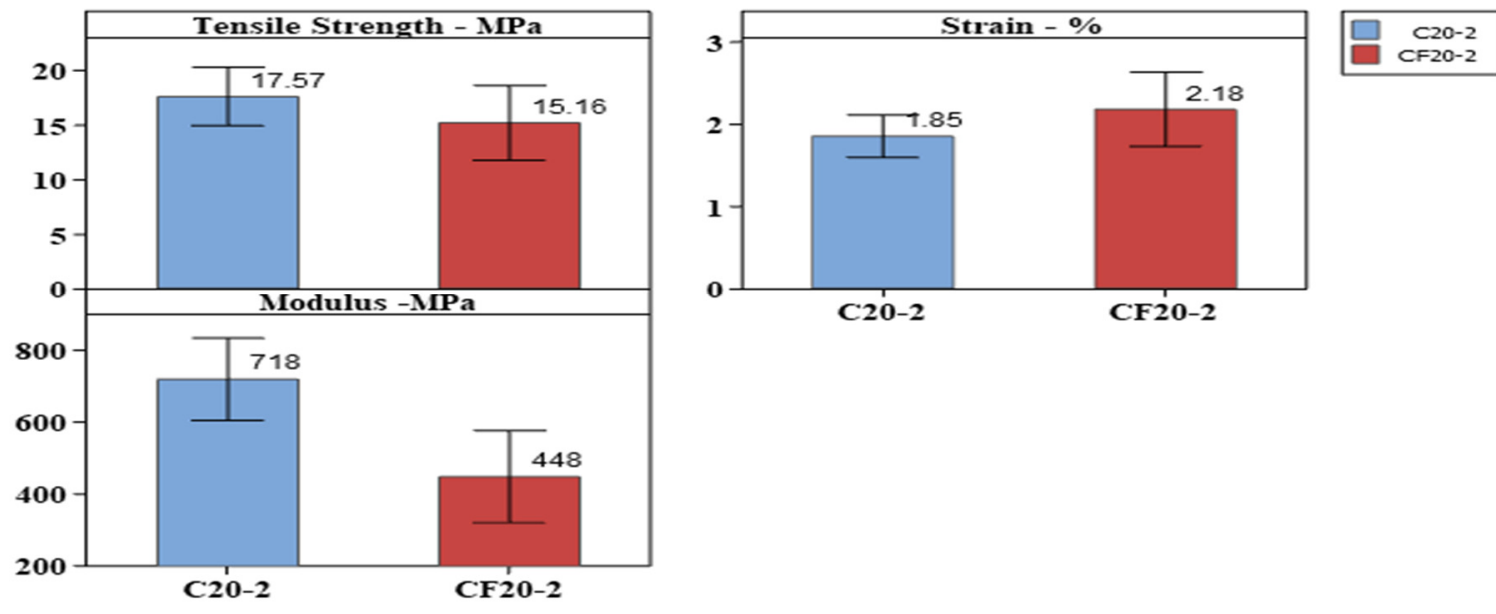

Fig. 9: Tensile Properties for Composites C20-2 (bagasse fiber reinforced composite) and CF20-2 (bagasse-cotton fabric reinforced composite)

It is observed from Fig. 10 that for bagasse-cotton fabric composites (CF10-2 and CF20-2) the tensile strength and strain had decreased with the increase in the fiber weight percentage. This was perhaps because during the manufacturing process, the epoxy resin had to pass through the fabric to wet out the fibers. Due to higher fiber weight percentage the fibers were not properly wetted out and the bond strength between the epoxy resin and the fibers tend to decrease. However this phenomenon is under further investigation and will be presented in future paper.

In addition, paired t-test is performed to check with the significance of difference between the two samples which indicate that there is significant difference in tensile strength $(\mathrm{T}-$ Value $=-2.79 ; \mathrm{P}-$ Value $=0.049)$ and tensile strain $\quad(\mathrm{T}-$ Value $=-8.07 ; \quad \mathrm{P}$-Value $=0.001)$ properties of CF20-2 and CF10-2 whereas difference in young's modulus $(\mathrm{T}-$ Value $=0.07 ; \mathrm{P}-$ Value $=0.950)$ was not significant.

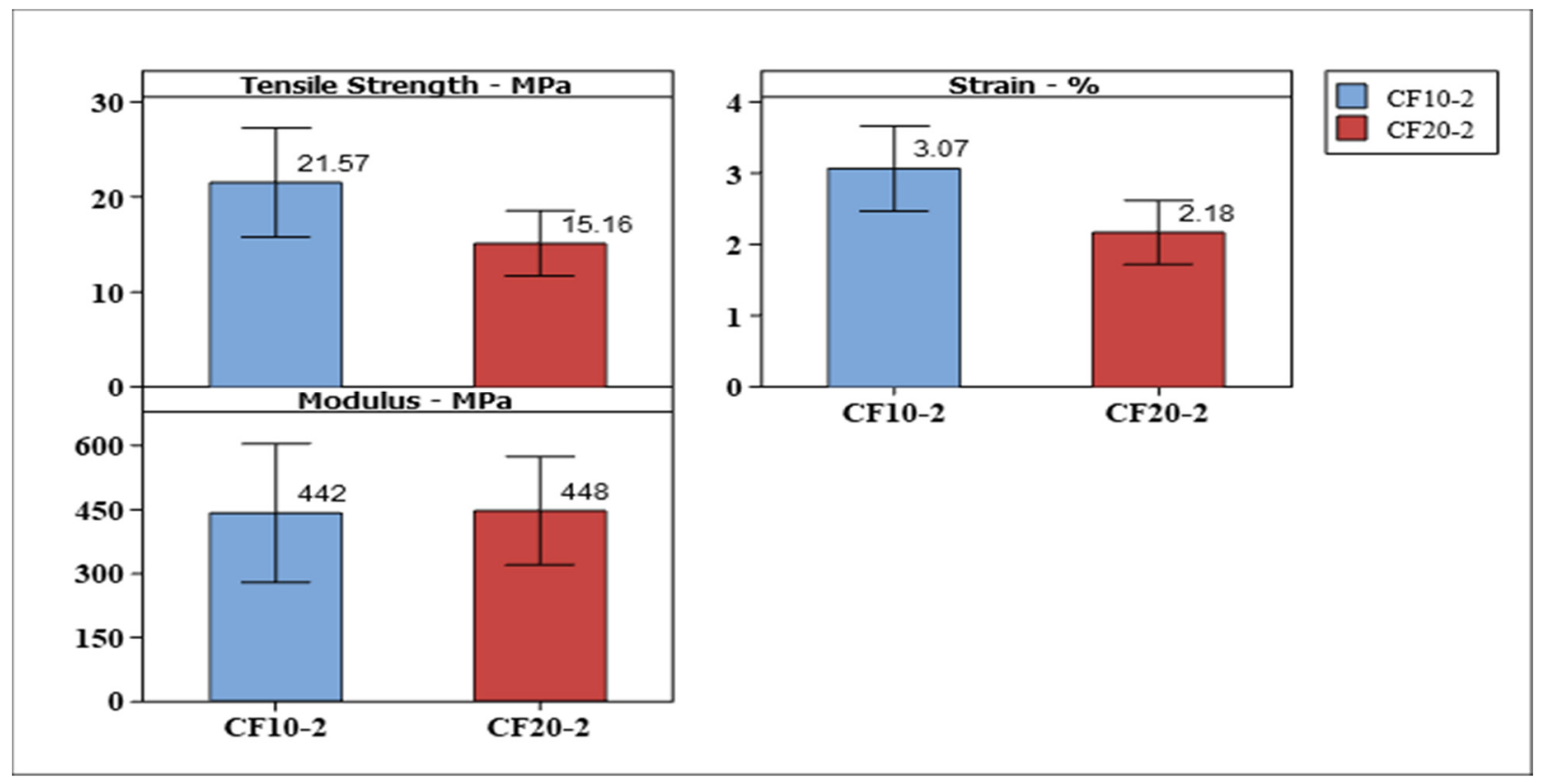

Fig. 10: Tensile Properties of bagasse-cotton fabric reinforced composites. 


\section{CONCLUSIONS}

- Bagasse fiber composites can easily be manufactured using bagasse fiber waste as reinforcement. These composite materials could find suitable applications in the non-structural composite material.

- The increase in the fiber weight percentage resulted in the improvement of tensile properties of bagasse fiber composites. It is a common practice that the fiber reinforcements are always added to enhance the properties of matrix.

- The increase in the fiber length also resulted in the slight improvement of tensile properties of bagasse fiber composites. This was perhaps because the longer length of fibers resulted in better bonding between the matrix and the fiber.

- The combination of cotton fabric with bagasse fibers was successfully used as the reinforcement to manufacture bagasse-cotton composites.

- The tensile properties of bagasse-cotton fabric reinforced composites had reduced with the increase of bagasse fiber weight percentage. This was perhaps because during the manufacturing process, the epoxy resin had to pass the fabric to wet out the fibers. Due to higher fiber weight percentage, the fibers were not properly wetted out and the bond strength between the epoxy resin and the fibers tend to decrease.

- The tensile strength for bagasse-cotton fabric reinforced composites was higher as compared to bagasse fiber composites. This may be due to improved bonding strength between cotton fabric and epoxy resin.

- The tensile strain for bagasse-cotton fabric composites was higher as compared to bagasse fiber composites. This could be due to higher elongation of cotton fabric.

\section{ACKNOWLEDGEMENT}

The authors wish to express their gratitude towards NED University of Engineering and Technology for moral support.

\section{REFERENCES}

1. Backer A., Dutton S., Kelly D., "Composite
Materials for Aircraft Structures", American Institute of Aeronautics and Astronautics, 2019.

2. Halpin J.C., The Role of the Matrix in Fibrous Composite Structures. In Seferis J.C., Nicolais I., (Eds.): The Role of the Polymetric Matrix in the Processing and Structural Properties of Composite Materials, Springer, Boston, M.A., 1983.

3. Imran M., Badshah S., Khan R., "Vibration Analysis of Cracked Composite Laminated Plate: A Review", Mehran University Research Journal of Engineering and Technology, Vol. 38, No. 3, pp. 705-716, 2019.

4. Jogi S. A., Baloch M. M., Chandio A. D., Memon I. A., Chandio G. S., "Evaluation of Impact Strength of Epoxy Based Hybrid Composites Reinforced with E-Glass/Kevlar 49", Mehran University Research Journal of Engineering and Technology, Vol. 36, No. 4, pp. 1009-1016, 2017.

5. Jawaid M., Khalil H. A., "Cellulosic/Synthetic Fibre Reinforced Polymer Hybrid Composites: A Review", Carbohydrate polymers, Vol. 86, No. 1, pp. 1-18, 2011.

6. Joseph S., Sreekala M., Oommen Z., Koshy P., Thomas S., "A Comparison of the Mechanical Properties of Phenol Formaldehyde Composites Reinforced with Banana Fibres and Glass Fibres", Composites Science and Technology, Vol. 62, No. 14, pp. 1857-1868, 2002.

7. Yuhazri M., Sihombing H., "A Comparison Process between Vacuum Infusion and Hand Layup Method toward Kenaf/Polyester Composite", International Journal of Basic and Applied Sciences, Vol. 10, No. 3, pp. 54-57, 2010.

8. Bledzki A., Gassan J., "Composites Reinforced with Cellulose Based Fibres", Progress in Polymer Science, Vol. 24, No. 2, pp. 221-274, 1999.

9. Venkateshwaran N., ElayaPerumal A., Jagatheeshwaran M., "Effect of Fiber Length and Fiber Content on Mechanical Properties of Banana Fiber/Epoxy Composite", Journal of Reinforced Plastics and Composites, Vol. 30, No. 19, pp. 1621-1627, 2011.

10. Santhosh J., Balanarasimman N., Chandrasekar R., Raja S., "Study of Properties of Banana Fiber Reinforced Composites", International Journal of 
Research in Engineering and Technology, Vol.3, No. 11, pp. 144-150, 2014.

11. Wambua P., Ivens J., Verpoest I., "Natural Fibres: Can They Replace Glass in Fibre Reinforced Plastics?", Composites Science and Technology, Vol, 63, No. 9, pp. 1259-1264, 2003.

12. Torgal F.P., Jalali S., "Natural Fiber Reinforced Concrete". In Fangueiro R., (Ed.), Fibrous and Composite Materials for Civil Engineering Applications Elsevier, Cambridge, 2011.

13. Nyior G. B., Mgbeahuru E. C., "Effects of Processing Methods on Mechanical Properties of Alkali Treated Bagasse Fibre Reinforced Epoxy Composite", Journal of Minerals and Materials Characterization and Engineering, Vol. 6, No. 3, p. 345, 2018.

14. Verma D., Gope P. C., Maheshwari M. K., Sharma R. K., "Bagasse Fiber Composites-a Review", Journal of Materials and Environmental Science, Vol. 3, No. 6, pp. 10791092, 2012.

15. Arjun V. R., Eldho P., Irfan C. H., Sadiq A. K. K., Anjaldev V. V., "Comparative Study of Mechanical Properties of Alkali Treated and Untreated Sugarcane Bagasse Fiber Reinforced Composite Material.", International Research Journal of Engineering and Technology, Vol. 5, No. 5, pp. 413-420, 2018.

16. Monteiro S. N., Candido V. S., Braga F. O., Bolzan L. T., Weber R. P., Drelich J.W., "Sugarcane Bagasse Waste in Composites for Multilayered Armor", European Polymer Journal, Vol. 78, pp. 173-185, May 2016.

17. ASTM D2256 / D2256M,"Standard Test Method for Tensile Properties of Yarns by the SingleStrand Method", D2256 / D2256M, 2015.

18. ISO 527-4,"Plastics -- Determination of Tensile Properties -- Part 4: Test Conditions for Isotropic and Orthotropic Fibre-Reinforced Plastic Composites", 1997.

19. Vilay V., Mariatti M., Taib R. M., Todo M., "Effect of Fiber Surface Treatment and Fiber Loading on the Properties of Bagasse FiberReinforced Unsaturated Polyester Composites", Composites Science and Technology, Vol. 68, No. 3-4, pp. 631-638, 2008.

20. Cao Y., Shibata S., Fukumoto I., "Mechanical Properties of Biodegradable Composites
Reinforced with Bagasse Fibre before and after Alkali Treatments", Composites part A: Applied science and Manufacturing, Vol. 37, No. 3, pp. 423-429, 2006.

21. Negawo T. A., Polat Y., Buyuknalcaci F. N., Kilic A., Saba N., Jawaid M., "Mechanical, Morphological, Structural and Dynamic Mechanical Properties of Alkali Treated Ensete Stem Fibers Reinforced Unsaturated Polyester Composites", Composite Structures, Vol. 207, pp. 589-597, 2019.

22. Yousfani S. H. S., Gong R. H., Porat I., "Effect of Process Variables on the Tensile Properties of Fibreglass Nonwoven Composites", Polymers and Polymer Composites, Vol. 24, No. 1, pp. 6570, 2016.

23. Thomason J. L., Vlug M. A., "Influence of Fibre Length and Concentration on the Properties of Glass Fibre-Reinforced Polypropylene: 1. Tensile and Flexural Modulus", Composites part A: Applied science and Manufacturing, Vol.27, No. 6, pp. 477-484, 1996.

24. Balaji A., Karthikeyan B., Swaminatha J., Sundar Raj C., "Effect of Filler Content of Chemically Treated Short Bagasse FiberReinforced Cardanol Polymer Composites", Journal of Natural Fibers, Vol. 16, No. 4, pp. 613-627, 2019.

25. Tehrani M., Boroujeni A., Hartman T., Haugh T., Case S., Al-Haik M., "Mechanical Characterization and Impact Damage Assessment of a Woven Carbon Fiber Reinforced Carbon Nanotube-Epoxy Composite", Composites Science and Technology, Vol. 75, pp. 42-48, February 2013.

26. Salleh F. M., Hassan A., Yahya R., Azzahari A. D., "Effects of Extrusion Temperature on the Rheological, Dynamic Mechanical and Tensile Properties of Kenaf Fiber/Hdpe Composites", Composites Part B: Engineering, Vol. 58, pp. 259-266, 2014.

27. Siddika S., Mansura F., Hasan M., "PhysicoMechanical Properties of Jute-Coir Fiber Reinforced Hybrid Polypropylene Composites", International Journal of Chemical, Molecular, Nuclear, Materials and Metallurgical Engineering, Vol. 7, No. 1, pp. 60-64, 2013. 